\title{
COMUNICAÇÃO
}

\section{MULTIPLE DRUG REGIMEN FOR SEVERE DIARRHEA ASSOCIATED WITH CRYPTOSPORIDIUM IN AIDS PATIENTS}

\author{
Carlos Brites, Edson D. Moreira Jr., José Carlos Bina, \\ Warren D. Johnson Jr. and Roberto Badaró
}

Cryptosporidium is one of the most commonly identified causes of chronic diarrhea and malabsorption in AIDS patients ${ }^{1}$. The severity of human cryptosporidiosis in AIDS patients can be correlated with the degree of immune dysfunction that they present ${ }^{4} 5$. Several attempts at therapy of cryptosporidiosis have not been successsful and this disease remains without an effective treatment ${ }^{6} 7$. This communication presents an alternative association therapy to control severe diarrhea in AIDS patients with cryptosporidiosis.

We treated one patient with diarrhea caused by Crysptosporidium with spiramycin without success. After introduction of co-trimoxazole and doxycyclin for prophylaxis of Pneumocystis carinii pneumonia and treatment of chlamydial urethritis, respectively, he had a complete recovery of symptoms.

After this first case, five consecutive patients with chronic diarrhea caused by Cryptosporidium were treated with a combination of spiramycin (50 $\mathrm{mg} / \mathrm{kg} /$ day $)$, doxycyclin $(4 \mathrm{mg} / \mathrm{kg} /$ day) and co-trimoxazole (TMP-SMX - 25/5 mg/kg/day).

All patients had a history of diarrhea of $30-45$ days duration, (mean 38 days), with 10-15 episodes/daily, and loss of more than $10 \%$ of their body weight.

Prior to treatment, all patients had only cryptosporidia identified in their stool (modified ZiehlNeelsen staining) ${ }^{3}$. Stcol cultures on selective media for Salmonella, Shigella, and Campylobacter were negative. Two patients showed progressive clinical improvement, after 5 days of treatment with a complete recovery after 10 days. Two patients had an improvement after 8 days with disappearance of symptons after the $15^{\text {th }}$ day. The last patient had persistent severe diarrhea during three weeks after

Federal University of Bahia, Salvador, BA, Brazil. Cornell University Medical College, New York, NY, USA.

This work was supported by the NIH Grant AI26506-03

Address: Dr. Roberto Badaró. Servico de Imunologia do Hospital Prof. Edgard Santos. R. Joāo das Botas s/n Canela, 40140 Salvador, BA, Brasil

Recebido para publicação em 04/10/90. interruption of treatment. An endoscopic study and biopsy of his colon showed no abnormalities.

All five patients had a negative stool examination for Cryptosporidium after completing treatment, and remained asymptomatic during three months of follow-up.

The medication was well tolerated, and no significant side-effects were observed. Two patients experienced mild nausea. We conclude that this combination therapy may be useful in the treatment of cryptosporidiosis in AIDS patients but requires further evaluation.

\section{REFERENCES}

1. Center for Disease Control: Update: Treatment of cryptosporidiosis in patients with acquired immunodeficiency syndrome (AIDS). MMWR 33: 117, 1984.

2. Garcia LS, Bruckner DA, Brewer TC, Shimizu RY. Techniques for the recovery and identification of Cryptosporidiosis oocysts from stool specimens. Journal of Clinical Microbiology 18: 185-90, 1983.

3. Ma P, Soave R. Three-step stool examination for cryptosporidiosis in 10 homosexual men with protacted watery diarrhea. The Journal of Infectious Diseases 147: 824-828, 1983.

4. Margulis SJ, Honig CL, Soave R, Govani AF, Mouradian JA, Jacobson IM. Biliary tract obstruction in the acquired immunodeficiency syndrome. Annals of Internal Medicine 105: 207-210, 1986.

5. Pitlik SD, Fainstein V, Garza D, Guarda L, Bolivar R, Rios A, Hopfer RL, Mausel PA. Human cryptosporidiosis: Spectrum of disease. Report of six cases and review of the literature. Archives of Internal Medicine 143: 2269-2275, 1983.

6. Soave R, Armstrong D. Cryptosporidium and cryptosporidiosis. Reviews of Infectious Diseases 8: 10121023, 1986.

7. Soave R, Dieterich D, Kotler D, Gassyur E, Tiemey AR, Libes L, Legendre R. Oral diclurazil therapy for Cryptosporidiasis. In: Abstract of Sixth International Conference on AIDS, San Francisco no ThB 520, June, 1990. 